\title{
Análise da atividade antimicrobriana do extrato hidroalcoólico das folhas de Terminalia catappa contra Staphyloccocus aureus e Staphylococcus aureus resistente a meticilina - MRSA
}

\author{
Analysis of the antimicrobial activity of the hydroalcoholic extract of Terminalia catappa \\ leaves against Staphylococcus aureus and methicillin resistant Staphylococcus aureus
}

Danilo de Araújo Morais ${ }^{1,3}$, Luis Felipe Lima Lobato ${ }^{2,3}$, José Lima Viana ${ }^{3}$, Adrielle Zagmignan4, Gesanaje da Paz Carvalho ${ }^{3}$, Gabrielle Guedes Coutinho ${ }^{3}$, Aline de Oliveira Rezende ${ }^{3}$, Eldimara Santos Alves ${ }^{3}$, Carlos Eduardo Campos Maramaldo ${ }^{5,3}$, Raquel Ferreira Rocha ${ }^{1,3}$, Lídio Gonçalves Lima Neto ${ }^{3}$, Eduardo Martins de Sousa ${ }^{3}$.

\begin{abstract}
Resumo: Staphylococcus aureus está presente na microbiota normal humana, sendo encontrada na região das narinas, pele e trato gastrointestinal. Tem sido um dos principais microrganismos relacionados a infecções hospitalares, provocando na maioria das vezes abcessos cutâneos e infecções de feridas, mas também podem causar infecções sistêmicas como: bacteremia, endocardite, pneumonia, dentre outras. Os antibióticos são indicados no tratamento de infecções bacterianas, entretanto, seu uso indiscriminado propicia o desenvolvimento de resistência, representando um sério problema de saúde pública. Logo, é necessário a investigação de alternativas para o tratamento dessas infecções, como por exemplo, a utilização de produtos naturais para fins terapêuticos. Diante disso, esse estudo objetivou investigar a atividade antimicrobiana de Terminalia catappa (amendoeira-da-praia) contra Staphylococcus aureus (ATCC 25923) e Staphylococcus aureus resistente a meticilina - MRSA (ATCC 343602). As folhas foram coletadas, secas, trituradas e ressuspendidas em etanol $99,5 \%$. Realizou-se a investigação da atividade antimicrobiana in vitro pelo ensaio de difusão em ágar, seguido pelo ensaio de microdiluição em caldo. Os resultados mostraram atividade antimicrobiana contra as cepas bacterianas testadas, apresentando uma concentração inibitória mínima de $0,36 \mathrm{mg} / \mathrm{mL}$ para Staphylococcus aureus e $0,29 \mathrm{mg} / \mathrm{mL}$ para MRSA. Os resultados obtidos indicam um grande potencial dessa espécie vegetal na pesquisa e desenvolvimento de novos agentes antimicrobianos.
\end{abstract}

Palavras-chave: Terminalia catappa L. Amendoeira-da-praia. Antimicrobiano. Staphylococcus.

Abstract: Staphylococcus aureus is present in the normal human microbiota, being the region of the nostrils, skin and gastrointestinal tract. It has been one of the main microorganisms related to nosocomial infections, most of which causes cutaneous abscesses and wound infections, but also can cause systemic infections such as: bacteremia, endocarditis, pneumonia, among others. Antibiotics are indicated in the treatment of bacterial infections; however, their indiscriminate use leads to the development of resistance, representing a serious public health problem. Therefore, it is necessary to investigate alternatives for the treatment of these infections, such as the use of natural products for therapeutic purposes. The objective of this study was to investigate the antimicrobial activity of Terminalia catappa (beach almond) against Staphylococcus aureus (ATCC 25923) and methicillin resistant Staphylococcus aureus - MRSA (ATCC 343602). The leaves were collected, dried, crushed and resuspended in $99.5 \%$ ethanol. Antimicrobial activity was investigated in vitro by the agar diffusion assay, followed by the broth microdilution assay. The results showed antimicrobial activity against the bacterial strains tested, presenting a minimum inhibitory concentration of $0.36 \mathrm{mg} / \mathrm{mL}$ for Staphylococcus aureus and $0.29 \mathrm{mg} / \mathrm{mL}$ for MRSA. The results indicate a great potential of this plant species in the research and development of new antimicrobial agents.

Keywords: Terminalia catappa. Beach almond tree. Antimicrobial. Staphylococcus.

\footnotetext{
${ }^{1}$ Universidade CEUMA, Biomedicina (Maranhão, Brasil)

2 Universidade CEUMA, Programa de Pós-graduação em Biologia Parasitária (Maranhão, Brasil)

3 Universidade CEUMA, Laboratório de Imunologia e Microbiologia de Infecções Respiratórias (Maranhão, Brasil)

${ }^{4}$ Universidade CEUMA, Laboratório de Imunologia das doenças infecciosas e parasitárias (Maranhão, Brasil)

${ }^{5}$ Universidade CEUMA, Farmácia (Maranhão, Brasil)
}

Autor correspondente: Biomédico, Luis Felipe Lima Lobato. Mestrando no Programa de Pós-Graduação em Biologia Parasitária, Universidade Ceuma (Maranhão, Brasil). Rua 04, nª 48, Cohatrac II. CEP: 65054300, São Luís, MA, Brasil. Tel.: (98) 99901-9836. 


\section{Introdução}

Staphylococcus aureus está presente na microbiota normal humana, na região das narinas, pele e trato gastrointestinal ${ }^{1}$. É dito como um dos principais agentes de infecções hospitalares, sendo na maioria das vezes infecções superficiais (abcessos cutâneos, infecções de feridas), mas também podem causar infecções sistêmicas, como bacteremia, endocardite, pneumonia, dentre outras ${ }^{2}$.

Percebe-se ainda, uma marcante capacidade desse microrganismo em desenvolver resistência aos antimicrobianos ${ }^{1}$. Embora a penicilina tenha sido largamente utilizada para o tratamento de infecções por Staphylococcus $s p$. No fim de 1940, a resistência a este fármaco já havia aumentado de tal modo que não era eficaz para o tratamento de infecções por $S$. aureus ${ }^{2}$. Similarmente, introduziu-se a meticilina para o tratamento de infecções por $S$. aureus, o que também resultou em resistência bacteriana, sendo 2 anos após caracterizado como $S$. aureus multirresistente (MRSA). MRSA, desde então, se espalhou pelo mundo e agora é endêmica em hospitais e serviços de saúde da maioria dos países industrializados ${ }^{3,4}$.

O surgimento de cepas MRSA é um desafio importante no tratamento de bactérias do gênero Staphylococcus, uma vez que estas são predominantemente resistentes a todos os $\beta$-lactâmicos disponíveis pela indústria farmacêutica ${ }^{5,6}$.

A utilização de plantas como recurso para o tratamento de doenças vem desde o início da história da humanidade ${ }^{7}$. Sabendo que as plantas são importantes fontes naturais de recursos medicamentosos ${ }^{7}$, com vários princípios ativos com ação farmacológica, é importante a investigação de novos metabólitos derivadas de produtos naturais, para o tratamento de algumas doenças infecciosas, principalmente as bacterianas devido a capacidade destes microrganismos adquirirem resistência aos antibióticos ${ }^{8}$.

A Terminalia catappa é uma espécie arbórea originária da Malásia pertencente à família Combretaceae, que pode atingir de 25 a 40 metros de altura, os constituintes presentes nos extratos polares das folhas desta planta são principalmente compostos polifenólicos, em especial os taninos ${ }^{9,10}$. Mediante Cromatografia Líquida de Alta Eficiência (CLAE), foi possível observar a presença desses taninos hidrolisáveis em plantas dessa espécie cultivadas ao longo da orla das praias da cidade de Santos (SP), tendo como compostos majoritários taninos tais como o ácido gálico ${ }^{11}$.

Os taninos hidrolisáveis consistem de ésteres de ácidos gálicos glicosilados, formados a partir de ácidos chiquímicos, onde os grupamentos hidroxilas são esterificados com os ácidos fenólicos ${ }^{12}$. Várias plantas que apresentam na sua constituição essas moléculas são tradicionalmente usadas para distúrbios gástricos, e estudos já demonstraram que entre as atividades biológicas desse grupo estão as ações antiulcerogênica e antissecretória, assim como também é relatada a atuação na proteção da mucosa gástrica por danos causados por agentes necrosantes ${ }^{13}$.

Este trabalho, portanto, objetivou avaliar a atividade antimicrobiana do extrato hidroalcoólico das folhas de Terminalia catappa contra Staphylococcus aureus e sua cepa resistente a meticilina - MRSA.

\section{Material e métodos}

\section{Colheita e Preparação das Folhas de Terminalia Catappa L.}

As folhas de Terminalia catappa (exsicata № 01062) foram coletadas no Herbário Ático Seabra da Universidade Federal do Maranhão - UFMA às 06:00 em dia onde não houve ocorrência de chuva na noite anterior, pois a incidência longa da luz solar e da chuva podem 
interferir na produção dos metabolitos secundários das plantas. Após a colheita, as folhas foram limpas com papel toalha e selecionadas, descartando aquelas já secas ou com presença de fungos. Em seguida as folhas selecionadas foram espalhadas sobre uma mesa para 0 processo de secagem in natura das mesmas. Após 72 horas, as folhas foram trituradas em moinho elétrico e o pó obtido foi então medido em proveta graduada.

\section{Obtenção do Extrato Hidroalcoólico TcHE}

O processo de extração dos metabolitos das folhas ocorreu por maceração, onde foi utilizada uma mistura de álcool etílico $\left(\mathrm{C}_{2} \mathrm{H}_{6} \mathrm{O}\right)$ com água destilada (solução hidroalcoólica $70 \%$ ) como solvente. $\mathrm{O}$ volume de solvente utilizado foi o de três vezes o volume do soluto (pó das folhas). Após 72 horas foi realizada a primeira filtragem do extrato, com auxílio de um funil e papel filtro. $O$ volume filtrado foi medido em proveta graduada e a quantidade obtida foi então reposta com mais solvente para a mistura inicial. O mesmo processo foi repetido mais duas vezes, sempre a cada três dias, sendo que a terceira vez foi obtido o filtrado final da maceração e a solução obtida das três filtragens foi misturada e medida. Após esse processo de extração, - volume obtido foi submetido à rotoevaporação para a eliminação da fração alcoólica do extrato.

\section{Atividade Antimicrobiana in vitro}

Microrganismos

Foram utilizadas as cepas das bactérias Staphylococcus aureus (ATCC 25923); Staphylococcus aures resistente a meticilina - MRSA (ATCC 343602).

Preparo das suspensões bacterianas

Os microrganismos foram inicialmente reativados a partir das suas culturas originais e mantidos em meio líquido $\mathrm{BHI}$ (Brain Heart Infusion) a $37^{\circ} \mathrm{C}$ por $24 \mathrm{~h}$. Posteriormente as amostras foram cultivadas em placas Ágar MuellerHinton a $37^{\circ} \mathrm{C}$ por $18-24$ h. Colônias isoladas foram então ressuspendidas em $5 \mathrm{~mL}$ de solução fisiológica (NacL) $0,89 \%$ estéril até atingir uma turbidez equivalente na escala de 0,5 de Mc.Farland $\left(1,5 \times 10^{8}\right.$ bactérias $/ \mathrm{mL}$ ).

\section{Avaliação da Sensibilidade Bacteriana}

As bactérias foram testadas inicialmente através do método de difusão em ágar de acordo com as normas da $\mathrm{CLSI}^{14}$, utilizando meio ágar MuellerHinton, onde cada placa foi semeada com swab molhado pelo inóculo de cada bactéria, e em seguida, foram perfurados sete poços, onde foram adicionados $30 \mu \mathrm{L}$ do extrato em cada um dos poções, nas concentrações $150 \mathrm{mg} / \mathrm{mL}, 75 \mathrm{mg} / \mathrm{mL}$, $34,5 \mathrm{mg} / \mathrm{mL}$ e $17,25 \mathrm{mg} / \mathrm{mL}$ do extrato hidroalcoólico de Terminalia catappa (TcHE) além do Controle Negativo (salina 0,9\%) e Controle Positivo (Cloranfenicol), em seguida as placas foram incubadas a $37^{\circ} \mathrm{C}$ por 24 horas. Após a incubação, foi observado a presença ou não de halo de inibição, e medido o diâmetro dos mesmos com o auxílio de um paquímetro. Os ensaios foram realizados em triplicatas.

Determinação da Concentração Inibitória Mínima (CIM)

A determinação da CIM foi realizada pela técnica de microdiluição em placa. Para isso, cada suspensão microbiana foi reativada e ajustada a quantidade em escala de MacFarland 0,5. Em seguida, foi feito uma diluição de 1:10 em caldo Mueller Hinton. Após isso, foram transferidos $20 \mu \mathrm{L}$ para uma placa de 96 poços distribuídos da seguinte forma: coluna 1 foi feito o Controle Negativo (meio + inóculo); a coluna 2 utilizou-se como Controle Positivo (meio + antibiótico + inóculo); a coluna 3 ficou como controle de pureza do meio (meio puro) e as colulas 4 a 16, foi realizado uma diluição seriada do TcHE iniciando na 
concentração de $50 \mathrm{mg} / \mathrm{mL}$, além da adição de meio e do inóculo bacteriano. $O$ volume final foi de $200 \mu \mathrm{L}$ por poço e os ensaios foram realizados em triplicatas. Após a preparação do ensaio, a placa foi incubada a $37^{\circ} \mathrm{C}$ por 24 horas. A revelação da paca foi feita pela adição de $30 \mu \mathrm{L}$ de Resazurina $0,03 \%$ por poço e incubado novamente por 30 minutos. A CIM $(\mathrm{mg} / \mathrm{mL})$ foi estabelecida como a menor concentração do TcHE onde não houve alteração da coloração. Determinação da Concentração Bactericida Mínima (CBM)

Para determinação da CBM foi utilizada a placa do teste de CIM. Uma alíquota de $10 \mu \mathrm{L}$ de cada poço foi incubada em placas de Mueller Hinton e posteriormente as placas foram incubadas a $37^{\circ} \mathrm{C}$ por 24 horas. A CBM foi dita como a menor concentração do extrato no qual não houve crescimento bacteriano significativo sobre a superfície do ágar inoculado (90\% de morte microbiana).

\section{Resultados}

\section{Atividade Antimicrobiana por difusão em agar}

Nos controles negativos (Salina $0,9 \%)$ não houve a formação de halo de inibição, já em TcHE, assim como o controle positivo (antibiótico) houve a formação de halo para Staphylococcus aureus nas concentrações do TcHE em 50 $\mathrm{mg} / \mathrm{mL}(23,6 \pm 1,5 \mathrm{~mm}), 25 \mathrm{mg} / \mathrm{mL}(21 \pm$ $1 \mathrm{~mm}), 12, \mathrm{mg} / \mathrm{mL}(16,3 \pm 1,5 \mathrm{~mm}), 6,25$ $\mathrm{mg} / \mathrm{mL}(11 \pm 1 \mathrm{~mm})$, e para MRSA nas mesmas concentrações do TcHE formou halos de $30 \pm 0,5 \mathrm{~mm}, 28,6 \pm 0,5 \mathrm{~mm}, 26,3$ $\pm 1 \mathrm{~mm}$ e $24 \pm 1 \mathrm{~mm}$. O antibiótico utilizado como controle positivo foi o Cloranfenicol $1 \mu \mathrm{g} / \mathrm{mL}$. Como controle negativo, utilizouse salina $0,9 \%$. Conforme demonstrado na tabela 1.

\section{Determinação da Concentração Inibitória Mínima (CIM) e Concentração Bactericida Mínima (CBM)}

Para determinar a concentração inibitória mínima (CIM) e concentração bactericida mínima (CBM) foi utilizada a técnica de microdiluição em caldo. Foram realizadas culturas bacterianas em microplacas e incubadas com diferentes concentrações do extrato hidroalcoólico de $T$. catappa, e logo em seguida foi determinado os valores de CIM por Resazurina 0,03 \%, seguido da semeadura em ágar Mueller-Hinton.

Tabela 1 - Avaliação da atividade antimicrobiana de TcHE por teste de difusão em ágar

\begin{tabular}{|c|c|c|c|c|c|c|}
\hline \multirow{2}{*}{ Espécie } & \multicolumn{6}{|c|}{ Halo de inibição em mm (média \pm DP) } \\
\hline & C.cha & $\operatorname{CeN} N^{b}$ & $50 \mathrm{mg} / \mathrm{mL}$ & $25 \mathrm{mg} / \mathrm{mb}$ & $12,5 \mathrm{mg} / \mathrm{mb}$ & $6,25 \mathrm{mg} / \mathrm{mb}$ \\
\hline $\begin{array}{l}\text { Sacareus. } \\
\text { (ATCC 25923) }\end{array}$ & $\begin{array}{c}29 \pm 1 \\
(0,7)\end{array}$ & 0 & $23,7 \pm 1,5$ & $\begin{array}{l}21 \pm 1 \\
(p=0,6)\end{array}$ & $\begin{array}{c}16,33 \pm 1,5 \\
(p=0,4)\end{array}$ & $\begin{array}{c}11 \pm 1 \\
(p=0,3)\end{array}$ \\
\hline $\begin{array}{l}\text { MRSA } \\
\text { (ATCC 343602) }\end{array}$ & $\begin{array}{c}24,67 \pm 1,53 \\
\quad(p=0,4)\end{array}$ & 0 & $30,3 \pm 0,5$ & $\begin{array}{c}28,6 \pm 0,5 \\
(p=0,2)\end{array}$ & $\begin{array}{c}26,3 \pm 0,5 \\
(p=01)\end{array}$ & $\begin{array}{l}24 \pm 1 \\
(p=0,1)\end{array}$ \\
\hline
\end{tabular}

a:Controle Positivo: Cloranfenicol $1 \mu \mathrm{g} / \mathrm{mL}$. ${ }^{\mathrm{b}}$ :Controle Negativo: Salina 0,9\%.

* Valor de $p$ quando comparado ao grupo de $50 \mathrm{mg} / \mathrm{mL}$. 
Mostraram a concentração mínima do extrato capaz de inibir o crescimento bacteriano e a menor concentração capaz de matar as bactérias testadas. Esses testes apenas foram realizados com as bactérias que apresentaram sensibilidade às concentrações testadas no método de difusão em ágar. Para $S$. aureus a CIM foi de $036 \mathrm{mg} / \mathrm{mL}$, e a CBM foi de $1,56 \mathrm{mg} /$ $\mathrm{mL}$; enquanto que para MRSA o valor da CIM foi de $0,29 \mathrm{mg} / \mathrm{mL}$ e a CBM apresentou 4,68 $\mathrm{mg} / \mathrm{mL}$. Conforme demonstrado na tabela 2 .

\section{Discussão}

Os resultados encontrados foram relevantes para a inibição de $S$. aureus e $M R S A$, onde o TcHE foi capaz de inibir o crescimento dessas espécies por meio do teste de difusão em ágar, e apresentou dados importantes no que se refere a CIM e CBM para as bactérias testadas. Em outro estudo onde foi avaliado a atividade antimicrobiana da casca da T. catappa, foi observado ação do extrato sobre $S$. aureus, por meio do teste de difusão em ágar, sendo sensível a concentração de $100 \mathrm{mg} / \mathrm{mL}(7.33 \mathrm{~mm} \pm 0.58)$ do extrato testato ${ }^{15}$. Também, neste mesmo estudo, avaliou-se a concentração inibitória mínima, corroborando com os nossos dados, sendo o resultado de $80 \mathrm{mg} / \mathrm{mL}$ capaz de inibir o crescimento de $S$. aureus , porém nota-se que foi necessário uma concentração alta para a inibição do crescimento bactéria, sendo que em nossos resultados, utilizando o extrato das folhas de Terminalia catappa, o CIM foi de $0,36 \mathrm{mg} / \mathrm{mL}^{15}$. O TcHE teve uma ação também sobre a cepa resistente a meticilina da espécie (MRSA), apresentando sensibilidade de crescimento em todas as concentrações testadas $(50 \mathrm{mg} / \mathrm{mL}, 25 \mathrm{mg} / \mathrm{mL}, 12,5$ $\mathrm{mg} / \mathrm{mL}$ e $6,25 \mathrm{mg} / \mathrm{mL}$ ). Num estudo em que avaliou-se o extrato metanólico de folhas de $T$. catappa, observou-se a determinação do CIM $(1,56 \mathrm{mg} / \mathrm{mL})$ e CBM $(1,56 \mathrm{mg} / \mathrm{mL})$ para $S$. aureus e para $\operatorname{MRSA}(\mathrm{CIM}=1,04 \mathrm{mg} / \mathrm{mL}$ e $\mathrm{CBM}=150$ $\mathrm{mg} / \mathrm{mL})^{16}$, resultados bem semelhantes aos encontrados em nosso trabalho avaliando o extrato hidroalcoólico, visto que para $S$. aureus encontramos um CIM de $0,36 \mathrm{mg} / \mathrm{mL}$ e CBM de $1,56 \mathrm{mg} / \mathrm{mL}$, e para MRSA 0,29 mg/mL (CIM) e 4,68 $\mathrm{mg} / \mathrm{mL}$ (CBM).

Tabela 2 - Determinação da Concentração Inibitória Mínima (CIM) e Concentração Bactericida Mínima (CBM) do TcHE

\begin{tabular}{ccc}
\hline Espécie & CIM & CBM \\
\hline Staphylococcus aureus (ATCC 25923) & $036 \mathrm{mg} / \mathrm{mL}$ & $1,56 \mathrm{mg} / \mathrm{mL}$ \\
MRSA (ATCC 343602) & $0,29 \mathrm{mg} / \mathrm{mL}$ & $4,68 \mathrm{mg} / \mathrm{mL}$ \\
\hline
\end{tabular}




\section{Conclusões}

O extrato hidroalcoólico das folhas de Terminalia catappa, demonstrou um potencial antimicrobiano contra Staphylococcus aureus (ATCC 25923), e MRSA (ATCC 343602). Estes resultados abrem a possibilidade para novos estudos como curativos antimicrobiano, desinfetantes e muitas outras soluções antissépticas e que pretendemos em estudos futuros elucidar as composições químicas do extrato.

\section{Agradecimentos}

A todos os pesquisadores do Laboratório de Imunologia e Microbiologia das Infecções Respiratórias (LIMIR) da Universidade Ceuma que colaboraram para a realização deste estudo.

Apoio financeiro: $O$ presente trabalho foi realizado com apoio da Coordenação de Aperfeiçoamento de Pessoal de Nível Superior - Brasil (CAPES) - Código de financiamento 001. CEUMA. FAPEMA (BM-05016/17, UNIVERSAL-01468/16)

\section{Referências}

1. Foster, Timothy J. et al. Adhesion, invasion and evasion: the many functions of the surface proteins of Staphylococcus aureus. Nature Reviews Microbiology, v. 12, n. 1, p. 49, 2014.

2. Tong, Steven YC et al. Staphylococcus aureus infections: epidemiology, pathophysiology, clinical manifestations, and management. Clinical microbiology reviews, v. 28, n. 3, p. 603-661, 2015.

3. Grundmann, Hajo et al. The dynamic changes of dominant clones of Staphylococcus aureus causing bloodstream infections in the European region: results of a second structured survey. Euro surveillance: bulletin Européen sur les maladies transmissibles

European communicable disease bulletin, 2014 .

4. Graves, Shawna F. et al. Sublytic concentrations of Staphylococcus aureus Panton-Valentine leukocidin alter human PMN gene expression and enhance bactericidal capacity.Journal of leukocyte biology, v. 92, n. 2, p. 361-374, 2012.

5. Monecke, Stefan et al. Genotyping of Staphylococcus aureus isolates from diseased poultry. Veterinary microbiology, v. 162 , n. 2, p. 806-812, 2013.

6. Chan, Liana C. et al. Ceftobiprole-and ceftaroline-resistant methicillin-resistant Staphylococcus aureus. Antimicrobial agents and chemotherapy, v. 59, n. 5, p. 2960-2963, 2015.

7. Pimentel, Vitor Paiva et al. Biodiversidade brasileira como fonte da inovação farmacêutica: uma nova esperança?. Revista do BNDES, Rio de Janeiro, n. 43, p. 41-89, 2015.

8. Ashu Agbor, Michael; Naidoo, Sudeshni. Ethnomedicinal plants used by traditional healers to treat oral health problems in cameroon. Complementary and Alternative Medicine, 2015.

9. Sanches, J.H. Potencial invasor do Chapéu do Sol (Terminalia catappa L.) em área de restinga. Dissertação (Mestrado em Recursos Florestais) Escola Superior de Agricultura Luiz de Queiroz, Universidade de São Paulo, Piracicaba. 2009.

10. Rojas, Erika Guisante et al. Investigation of phenolic compounds with allelopathic potential in leaves of a tree invader of restinga (Terminalia catappa L.). Unisanta BioScience, v. 1, n. 2, p. 60-64, 2012.

11. Da Silva, Laísa Pinheiro; De Angelis, Célio Damacena; Toma, Walber. Avaliação da atividade antiulcerogênica do extrato etanólico obtido a partir das folhas de terminalia catappa I.(combretaceae). 2010. 
12. Monteiro, Julio Marcelino et al. Taninos: uma abordagem da química à ecologia. Química Nova, v. 28, n. 5, p. 892, 2005.

13. Khennouf, Seddik et al. Effect of tannins from Quercus suber and Quercus coccifera leaves on ethanol-induced gastric lesions in mice. Journal of agricultural and food chemistry, v. 51, n. 5, p. 1469-1473, 2003.

14. Rehm, Heidi L. et al. ACMG clinical laboratory standards for next-generation sequencing. Genetics in medicine, v. 15, n. 9 , p. 733, 2013.

15. Ajiboye, A. E. et al. Antibacterial Potency and Phytochemical Screening of the Bark of Terminalia catappa Against some Clinical Isolates. International Journal of Phytomedicine, v. 8, n. 2, p. 193-201, 2016

16. Mbengui, Rubens Dinzedi et al. Phytochemical screening and study of comparative antibacterial activity of aqueous and alcoholic extracts of the leaves and barks of Terminalia catappa on multiresistant strains. Journal of Applied Biosciences, v. 66, p. 5040-5048, 2013. 